\title{
Vulnerability within families headed by teen and young adult mothers investigated by child welfare services in Canada
}

\author{
W. Hovdestad, PhD; M. Shields; G. Williams, MSc; L. Tonmyr, PhD
}

This article has been peer reviewed.

Tweet this article

\section{Abstract}

Introduction: Young mothers' families are at increased risk of child maltreatment and other poor health and social outcomes.

Methods: Chi-square analyses of pooled child welfare services data from the Canadian Incidence Study of Reported Child Abuse and Neglect (CIS-2003; CIS-2008) were used to compare 284 teen mothers (18 years or younger) and 800 young mothers (19-21 years) and their families with 5752 families where the mother was 22 years or older.

Results: Twenty-six percent of young mothers were 18 years or younger. Most (68\% of teen-mother families and $57 \%$ of families with a young adult mother) received social assistance as their main source of income compared with $36 \%$ of families with a mother aged 22 years or older. Teen and young adult mothers were more likely than those aged 22 or older to have childhood histories of out-of-home care (31\% and $23 \%$ vs. $10 \%)$ and were more likely to have risk factors such as alcohol abuse $(25 \%$ and $23 \%$ vs. $18 \%)$ and few social supports ( $46 \%$ and $41 \%$ vs. $37 \%$ ). Secondary caregivers in families with young mothers also had more risk factors. Teen and young adult mother families were more likely to have their child placed out-of-home during the investigation $(29 \%$ and $27 \%$ vs. $17 \%$ ). All were equally likely to be victims of domestic violence and to have mental health issues.

Conclusion: Within this sample of high-risk families, young mothers' families were more at risk than comparison families. Mothers' youth may be a useful criterion to identify families for targeted interventions.

Keywords: child maltreatment, child abuse, family violence, teen mother, adolescent mother, out-of-home care, Canadian Incidence Study of Reported Child Abuse and Neglect

\section{Introduction}

Evidence shows that all the children born to young mothers, firstborn as well as subsequent children, and the mothers themselves, are at high risk of poor outcomes. ${ }^{1,2}$ As a result, young motherhood is a concern within the health, educational and social service sectors. In this paper, we use data from a cross-Canada sample of child maltreatment investigations conducted in either 2003 or 2008 to describe families with teen mothers (aged 18 years or younger) and young adult mothers (aged 19-21 years) involved with child welfare services and compare them to families with mothers aged 22 years and older. The families are described in terms of modifiable risk factors (e.g. alcohol abuse, low social support) that may be targeted by intervention or support programs.

In 2010, the rate of live births to mothers aged 15 to 17 years was 7.7 per 1000 females, and for mothers aged 18 to 19 years, 25.8 per 1000 females. $^{3}$ There were notable differences associated with place of residence: in
Key findings

- Data from child welfare agencies in Canada show that teen mothers have more challenges than older mothers.

- Teen mothers and the secondary caregivers in their homes are more likely to

- receive social assistance;

- have been placed in foster care or a group home as children; - abuse alcohol and/or drugs;

- have cognitive issues; and

- lack social support.

- Teen mothers have similar challenges to older mothers in terms of their mental health problems and exposure to intimate partner violence.

- Programs to prevent child maltreatment may need to be proactive connecting with young mothers at risk who are stressed on many fronts.

2006-2010, age-specific live birth rates among females aged 10 to 17 years ranged from 1.6 per 1000 in Quebec to 29.4 per 1000 in Nunavut. ${ }^{3}$ For women aged 18 to 19 years, age-specific live birth rates ranged from 17.8 per 1000 in British Columbia to 168.9 per 1,000 in Nunavut. ${ }^{3}$ Births to mothers aged 20 years or older represented $96 \%$ of the live births in Canada in 2009. ${ }^{4}$ Jutte et al. ${ }^{2}$ noted that $4.2 \%$ of Canadian live births in 2006 were to adolescents.

Provincial/territorial differences in rates of young motherhood may reflect, in part, differing culture-related opinions about its desirability. Evidence for positive outcomes for young mothers and their children, and the importance of cultural factors in shaping these outcomes, has been reviewed elsewhere. ${ }^{5}$ Nonetheless, the children of young

\section{Author reference:}

Surveillance and Epidemiology Division, Public Health Agency of Canada, Ottawa, Ontario, Canada

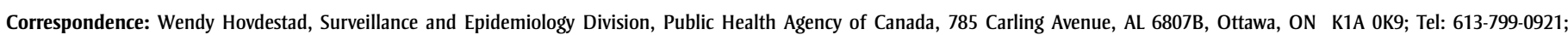
Email: wendy.hovdestad@phac-aspc.gc.ca 
mothers in Canada are at risk for poor health and developmental outcomes. ${ }^{2}$ Jutte et al. $^{2}$ studied a cohort of 32000 children born between 1979 and 1984 who were living in Winnipeg at age 17 years. Children born to adolescent mothers (6\%) and children born to prior adolescent mothers (i.e. the mother was adolescent when the oldest sibling was born, 10\%) were compared with children of women who had never been adolescent mothers. Children born to teen mothers or to mothers who gave birth to an older sibling during their teen years experienced mortality rates 2 to 4 times higher than children of other mothers. For a portion of the sample, data were available about interventions by child welfare services delivered when the children were aged between 8 and 17 years. Children of current or former teen mothers were 2 to 3 times more likely to have required these interventions. Half of all cohort children who were taken into foster care were children of current or prior adolescent mothers.

In other Canadian research, analyses of data from 1928 young adults in Ontario demonstrated that those who had a mother who was young (20 years or younger) when she gave birth to her first child were more likely to have experienced abuse (either physical or sexual) during childhood. ${ }^{6}$ This association was maintained after statistically controlling for family socioeconomic status.

Maltreatment in families headed by young mothers is of particular concern because maltreated infants and young children are very vulnerable to injury and death and are more likely to be judged to be sufficiently at risk to require out-of-home placement. $^{7-9}$ As one indicator of risk, deaths of Canadian children aged 0 to 17 years due to family-related homicide occur predominantly among infants aged less than 12 months. ${ }^{9}$ Due to their vulnerability, the need for immediate social service intervention may be greater compared with families with older mothers and older children.

Fallon et al. ${ }^{10}$ used data from the 2008 cycle of the Canadian Incidence Study of Reported Child Abuse and Neglect (CIS) to describe the characteristics of young Canadian parents whose families were investigated by child welfare services and to describe the services provided to these families. They found that $22 \%$ to $23 \%$ of biological mothers aged 21 years and younger had a history of foster care or of living in a group home compared to $10 \%$ of biological mothers aged 22 to 30 years. In other analyses of all primary biological caregivers aged younger than 31 years, the researchers found that having a history of institutional care was associated with ongoing services being offered to the family, as was having few social supports and mental health and/or alcohol or substance use issues. ${ }^{10}$

Thus, population-based and child welfarebased data indicate that families with young mothers have more risk factors for child maltreatment and more need of intervention by child welfare services. We used combined data from the CIS from 2003 (CIS-2003) and from 2008 (CIS2008) to describe families in Canada who were involved with child welfare services. The teen mothers, young mothers and their families are compared with families in which the mothers are 22 years or older.

\section{Methods}

\section{Data source}

This study is based on analyses of data collected in two cycles of the CIS in 2003 and 2008. Data were pooled from the two cycles to maximize sample size. The CIS identifies child maltreatment investigations from child welfare agencies across Canada during a three-month period in the autumn of the survey year. Child welfare workers fill out a three-page questionnaire on each investigated child four to eight weeks after receiving the allegation. The CIS excludes already open and screened out cases as well as cases opened for reasons other than child maltreatment. Data from Quebec were excluded from the CIS-2003 because of differences in collection methods and comparability of the data collected. More information about the CIS-2003 and CIS-2008 is available elsewhere. ${ }^{11,12}$ Note that the Aboriginal status of children and caregivers is recorded in the CIS, but consultations with Aboriginal organizations about culturally sensitive use of these data were not conducted, so these variables were not analyzed.

\section{Study sample}

Using the pooled CIS-2003 and CIS-2008 data sets, we selected all children for whom the primary caregiver was the biological mother. We divided the sample into three groups based on the age of the mother: teen mothers aged 18 years or younger ( $\mathrm{n}=284$ ); young adult mothers aged 19 to 21 years $(n=800)$ and mothers aged 22 years or older $(n=5752)$. Because of the potential stressors involved with having a young child, to increase comparability of the groups we only included families with at least one child under the age of 6 . If there was more than one child under the age of 6 , we selected the youngest biological child.

\section{Measures}

The questionnaire included data about the child (e.g. age and sex), the household (e.g. income source, overcrowding), the primary and secondary caregivers (e.g. sex, relationship to the child, and risk factors), service referrals made by the child welfare worker for any family member, and results of the investigation. Note that caregivers' ages were coded in ranges $(<16,16-18$, $19-21,22-30,31-40,41-50,51-60,>60$ years), limiting our ability to consider a more detailed breakdown based on the age of the mother.

For both the primary and secondary caregivers, the child welfare worker coded each risk factor as "Confirmed," "Suspected," "No" or "Unknown." We combined the percent of confirmed or suspected for alcohol abuse, drug/solvent abuse, cognitive impairment, mental health issues, few social supports, victim of domestic violence, history of foster care/group home and perpetrator of domestic violence. Cases where the child welfare worker indicated "Unknown" are included in the denominator (i.e. the caregiver is assumed not to have the risk factor).

CIS-2008 tracked two types of investigations: maltreatment investigations, where the person reporting to child welfare 
services believed that maltreatment had occurred, and risk investigations, where the person reporting believed the child was at risk of future maltreatment. CIS-2003 only includes maltreatment investigations. In each maltreatment investigation the child welfare worker could investigate any of the five main types of maltreatment (physical abuse, sexual abuse, neglect, emotional maltreatment and exposure to intimate partner violence) as primary, secondary or tertiary concerns. Each type of maltreatment investigated was coded by the child welfare worker as being "Substantiated," "'Suspected" or "Unfounded." We report the percent of investigations (combining primary, secondary and tertiary) by type of maltreatment and the percent substantiated among these investigations. A risk investigation was defined as being substantiated if the child protection worker indicated there was a significant risk of future maltreatment. A response of "unknown" was assumed to be "no."

\section{Analysis}

We used chi-square tests to detect differences between estimates for families with a young mother (teen or young adult mother) versus families with a mother aged 22 years or older, making the assumption that the CIS pooled sample was selected using simple random sampling. Because our focus was on examining factors associated with being a family with a young mother (as opposed to estimating population counts of families with young mothers) and due to concerns raised about the national representativeness of estimates based on CIS weighted data, ${ }^{13}$ all analyses are based on unweighted data. Analyses were conducted using SAS Enterprise Guide 5.1 (SAS Institute Inc., Cary, NC, US).

\section{Results}

In families where the primary caregiver was a young mother ( $<21$ years), $26 \%$ were 18 years or younger. The most common source of household income among families with a young mother as the primary caregiver was social assistance, other benefit or no income ( $68 \%$ for teen mothers aged $\leq 18 ; 57 \%$ for young adult mothers aged 19-21), compared with $36 \%$ for families with a mother aged 22 or older (Table 1). Families with a teen mother or mother aged 22 or older were equally likely to have a secondary caregiver living in the home $(57 \%$ and $59 \%$ respectively), while families with a young adult mother were less likely to have a secondary caregiver (52\%) The majority of teenmother families had another adult (other than the primary or secondary caregiver) living in the home (51\%), compared with
TABLE 1

Household, child and family characteristics among investigated families ${ }^{\mathrm{a}}$ where the primary caregiver was the biological mother, 2003 and 2008

\begin{tabular}{|c|c|c|c|c|c|c|}
\hline \multirow[t]{3}{*}{ Characteristics } & \multicolumn{6}{|c|}{ Age of mother, years } \\
\hline & \multicolumn{2}{|c|}{$\leq 18$} & \multicolumn{2}{|c|}{$19-21$} & \multicolumn{2}{|c|}{$\geq 22$} \\
\hline & $\mathbf{N}$ & $\%$ & $\mathbf{N}$ & $\%$ & $\mathbf{N}$ & $\%$ \\
\hline Total families & 284 & & 800 & & 5752 & \\
\hline \multicolumn{7}{|l|}{ Age of mother, years } \\
\hline$<16$ & 15 & 5.3 & - & - & - & - \\
\hline $16-18$ & 269 & 94.7 & - & - & - & - \\
\hline $19-21$ & - & - & 800 & 100.0 & - & - \\
\hline $22-30$ & - & - & - & - & 3170 & 55.1 \\
\hline $31-40$ & - & - & - & - & 2269 & 39.4 \\
\hline$\geq 41$ & - & - & - & - & 313 & 5.4 \\
\hline \multicolumn{7}{|l|}{ Age of child, years } \\
\hline Infant & 209 & $73.6^{*}$ & 382 & $47.8^{*}$ & 1265 & 22.0 \\
\hline 1 & 55 & 19.4 & 222 & $27.8^{*}$ & 1021 & 17.8 \\
\hline 2 & 15 & $5.3^{*}$ & 113 & 14.1 & 943 & 16.4 \\
\hline 3 & 5 & $1.8^{*}$ & 49 & $6.1^{*}$ & 836 & 14.5 \\
\hline $4-5$ & $\mathrm{x}$ & $x$ & 34 & $4.3^{*}$ & 1687 & 29.3 \\
\hline \multicolumn{7}{|l|}{ Sex of child } \\
\hline Girl & 133 & 46.8 & 376 & 47.0 & 2848 & 49.5 \\
\hline \multicolumn{7}{|l|}{ Main source of household income ${ }^{b}$} \\
\hline Social assistance/other benefit/none & 187 & $67.8^{*}$ & 448 & $57.4^{*}$ & 1984 & 36.0 \\
\hline Multiple jobs/seasonal work/employment insurance & 8 & $2.9^{*}$ & 65 & $8.3^{*}$ & 345 & 6.3 \\
\hline Part-time work & 24 & 8.7 & 57 & 7.3 & 388 & 7.0 \\
\hline Full-time work & 57 & $20.7^{*}$ & 211 & $27.0^{*}$ & 2796 & 50.7 \\
\hline Secondary caregiver lives in household & 162 & 57.0 & 418 & $52.3^{*}$ & 3366 & 58.5 \\
\hline Other adult(s) lives in household ${ }^{c}$ & 144 & $50.7^{*}$ & 230 & $28.8^{*}$ & 872 & 15.2 \\
\hline Home overcrowded & 38 & $13.4^{*}$ & 56 & 7.0 & 361 & 6.3 \\
\hline \multicolumn{7}{|l|}{ Number of moves in past year ${ }^{d}$} \\
\hline 0 & 72 & $32.6^{*}$ & 189 & $32.1^{*}$ & 2468 & 57.2 \\
\hline 1 & 75 & 33.9 & 231 & $39.3^{*}$ & 1212 & 28.1 \\
\hline 2 & 30 & $13.6^{*}$ & 82 & $13.9^{*}$ & 372 & 8.6 \\
\hline$\geq 3$ & 44 & $19.9^{*}$ & 86 & $14.6^{*}$ & 260 & 6.0 \\
\hline
\end{tabular}

Source: Canadian Incidence Study of Reported Child Abuse and Neglect, 2003 and 2008.

Note: Estimates based on youngest biological child if more than one child in family was investigated.

a The study only included families with one or more children under the age of 6 years. If there was more than one child under the age of 6 , we selected the youngest biological child.

${ }^{\mathrm{b}}$ Missing cases for main source of household income excluded ( $\mathrm{n}=8$ mothers aged $\leq 18$ years; $\mathrm{n}=19$ mothers aged 19-21 years; $\mathbf{n}=239$ mothers $\geq 22$ years).

c Excluding primary and secondary caregivers.

${ }^{\mathrm{d}}$ Missing cases for number of moves excluded ( $\mathrm{n}=63$ mothers $\leq 18$ years; $\mathrm{n}=212$ mothers $19-21$ years; $n=1440$ mothers $\geq 22$ years).

* Significantly different from mothers $\geq 22$ years $(p<.05)$.

$x$ Cell count less than 5 . 
$29 \%$ for families with a young adult mother and $15 \%$ for families where the mother was 22 or older. In $72 \%$ of the teen-mother families with another adult in the home, the other adult was a grandparent (data not shown). Teen-mother families were more likely to live in overcrowded conditions and both teen-mother families and families with a young adult mother were more likely to report multiple moves over the past year.

Young mothers were more likely than those aged 22 or older to have risk factors, including alcohol and drug abuse, cognitive impairment, and having few social supports, noted by the investigating child welfare worker (Table 2). Teen mothers were more likely than young adult mothers to have these risk factors noted. Mothers in all three groups were equally likely to be assessed as having mental health issues and being victims of domestic violence. Mothers aged 22 or older were more likely to be reported as having physical health issues. Young mothers were more likely to have had a history of foster care or living in a group home $(31 \%$ among teen mothers and $23 \%$ among young adult mothers) compared with $10 \%$ for mothers aged 22 or older. Having multiple risk factors was more common among young mothers; 3 or more risk factors were noted among 30\% of teen mothers and $29 \%$ of young adult mothers compared with $23 \%$ of mothers aged 22 or older.

In families where a secondary caregiver lived in the home (Table 3 ), this was most often the biological father $(61 \%$ for teen mothers, $69 \%$ for young adult mothers and $77 \%$ for mothers aged 22 or older). The grandmother was the second most common secondary caregiver for teenmother families (25\%) and a stepfather/ partner of the mother in families with a young adult mother (13\%) and families with a mother aged 22 or older (17\%). Secondary caregivers in families with a young mother were more likely to have risk factors noted by the child welfare worker including alcohol and drug abuse, cognitive impairment, having few social

TABLE 2

Mothers' risk factors among investigated families ${ }^{\mathrm{a}}$ where the primary caregiver was the biological mother

\begin{tabular}{|c|c|c|c|c|c|c|}
\hline \multirow[t]{3}{*}{ Risk factors } & \multicolumn{6}{|c|}{ Age of mother, years } \\
\hline & \multicolumn{2}{|c|}{$\leq 18$} & \multicolumn{2}{|c|}{ 19-21 } & \multicolumn{2}{|c|}{$\geq 22$} \\
\hline & $\mathbf{N}$ & $\%$ & $\mathbf{N}$ & $\%$ & $\mathbf{N}$ & $\%$ \\
\hline Total families & 284 & & 800 & & 5752 & \\
\hline Alcohol abuse & 72 & $25.4^{*}$ & 184 & $23.0^{*}$ & 1051 & 18.3 \\
\hline Drug/solvent abuse & 94 & $33.1^{*}$ & 229 & $28.6^{*}$ & 1069 & 18.6 \\
\hline Cognitive impairment & 48 & $16.9^{*}$ & 92 & $11.5^{*}$ & 414 & 7.2 \\
\hline Mental health issues & 69 & 24.3 & 212 & 26.5 & 1403 & 24.4 \\
\hline Physical health issues & 10 & $3.5^{*}$ & 40 & $5.0^{*}$ & 427 & 7.4 \\
\hline Few social supports & 131 & $46.1^{*}$ & 327 & $40.9^{*}$ & 2106 & 36.6 \\
\hline Victim of domestic violence & 103 & 36.3 & 359 & 44.9 & 2414 & 42.0 \\
\hline History of foster care/group home ${ }^{b}$ & 55 & $30.9^{*}$ & 112 & $23.3^{*}$ & 347 & 10.0 \\
\hline \multicolumn{7}{|l|}{ Total number of risk factors reported ${ }^{c}$} \\
\hline 0 & 51 & $18.0^{*}$ & 164 & $20.5^{*}$ & 1661 & 28.9 \\
\hline 1 & 86 & 30.3 & 231 & 28.9 & 1561 & 27.1 \\
\hline 2 & 63 & 22.2 & 172 & 21.5 & 1207 & 21.0 \\
\hline$\geq 3$ & 84 & $29.6^{*}$ & 233 & $29.1^{*}$ & 1323 & 23.0 \\
\hline
\end{tabular}

Source: Canadian Incidence Study of Reported Child Abuse and Neglect, 2003 and 2008.

a The study only included families with one or more children under the age of 6 years.

${ }^{\text {b }}$ Only asked in 2008 ( $n=178$ mothers aged $\leq 18$ years; $n=480$ mothers aged 19-21 years; $n=3479$ mothers aged $\geq 22$ years).

c Based on 7 items (alcohol abuse, drug/solvent abuse, cognitive impairment, mental health issues, few social supports, victim of domestic violence, physical health issues).

* Significantly different from mothers $\geq 22$ years $(p<.05)$. supports and/or having a history of living in foster care/group home. In all cases, secondary caregivers in teen-mother families were more likely than those in families with a young adult mother to have these risk factors noted. Secondary caregivers were equally likely in all family types to be reported as having mental and physical health issues. More than onequarter $(27 \%)$ of secondary caregivers in teen-mother families had 3 or more risk factors reported, compared with $23 \%$ for secondary caregivers in families with a young adult mother and $14 \%$ in families with a mother 22 years or older.

Children in families with a teen mother were more likely to be subjects of risk investigations than those in families with a mother aged 22 or older ( $31 \%$ vs. $17 \%$; Table 4$)$. Substantiation of risk investigations was equally likely among the three family types. Although children in teen-mother families were less likely to be subjects of maltreatment investigations compared with children in families with a mother aged 22 or older, maltreatment was equally likely to be substantiated. Children in families with a teen or young adult mother were more likely to be investigated for neglect while children in families with a mother aged 22 or older were more likely to be investigated for physical and sexual abuse. The same relationship was observed when the analysis was restricted to families where the child was two years old or younger (data not shown).

Emotional maltreatment investigations were more common among families with a young adult mother compared with children with mothers aged 22 or older $(18 \%$ vs. $15 \%)$. Exposure to intimate partner violence was less likely to be investigated among children with a teen mother $(20 \%)$ than children with a mother aged 22 or older $(29 \%)$, while this type of investigation was more likely for children with a young adult mother (33\%). The same relationship was observed when the analysis was restricted to families in which there was a biological father or mother's intimate partner living in the home (data not shown). For all five individual maltreatment types, substantiation of investigated maltreatment was equally likely to 
TABLE 3

Characteristics of secondary caregiver among investigated families ${ }^{\mathrm{a}}$ where the primary caregiver was the biological mother

\begin{tabular}{|c|c|c|c|c|c|c|}
\hline & \multicolumn{6}{|c|}{ Age of mother, years } \\
\hline & \multicolumn{2}{|c|}{$\leq 18$} & \multicolumn{2}{|c|}{ 19-21 } & \multicolumn{2}{|c|}{$\geq 22$} \\
\hline & N & $\%$ & $\mathbf{N}$ & $\%$ & $\mathbf{N}$ & $\%$ \\
\hline Total families ${ }^{b}$ & 162 & & 418 & & 3366 & \\
\hline \multicolumn{7}{|c|}{ Relationship of secondary caregiver to child ${ }^{c}$} \\
\hline Biological father & 99 & $61.1^{*}$ & 287 & $69.3^{*}$ & 2577 & 76.9 \\
\hline Stepfather/male partner of mother & 11 & $6.8^{*}$ & 52 & $12.6^{*}$ & 576 & 17.2 \\
\hline Grandmother & 40 & $24.7^{*}$ & 50 & $12.1^{*}$ & 100 & 3.0 \\
\hline Other male & 8 & $4.9^{*}$ & 16 & $3.9^{*}$ & 52 & 1.6 \\
\hline Other female & $\mathrm{x}$ & $\mathrm{x}$ & 9 & 2.2 & 45 & 1.3 \\
\hline Alcohol abuse & 59 & $36.4^{*}$ & 121 & $28.9^{*}$ & 826 & 24.5 \\
\hline Drug/solvent abuse & 65 & $40.1^{*}$ & 145 & $34.7^{*}$ & 674 & 20.0 \\
\hline Cognitive impairment & 21 & $13.0^{*}$ & 38 & $9.1^{*}$ & 198 & 5.9 \\
\hline Mental health issues & 24 & 14.8 & 52 & 12.4 & 434 & 12.9 \\
\hline Physical health issues & 11 & 6.8 & 19 & 4.5 & 185 & 5.5 \\
\hline Few social supports & 65 & $40.1^{*}$ & 132 & $31.6^{*}$ & 883 & 26.2 \\
\hline Victim of domestic violence & 21 & 13.0 & 57 & $13.6^{*}$ & 318 & 9.4 \\
\hline History of foster care/group home ${ }^{d}$ & 14 & $13.2^{*}$ & 31 & $11.2^{*}$ & 123 & 5.8 \\
\hline Perpetrator of domestic violence & 42 & $25.9^{*}$ & 153 & 36.6 & 1207 & 35.9 \\
\hline \multicolumn{7}{|l|}{ Total number of risk factors reported ${ }^{\mathrm{e}}$} \\
\hline 0 & 50 & $30.9^{*}$ & 164 & $39.2^{*}$ & 1607 & 47.7 \\
\hline 1 & 31 & 19.1 & 98 & 23.4 & 782 & 23.2 \\
\hline 2 & 37 & $22.8^{*}$ & 58 & 13.9 & 501 & 14.9 \\
\hline$\geq 3$ & 44 & $27.2^{*}$ & 98 & $23.4^{*}$ & 476 & 14.1 \\
\hline
\end{tabular}

Source: Canadian Incidence Study of Reported Child Abuse and Neglect, 2003 and 2008.

Note: Estimates based on youngest biological child if more than one child in family was investigated.

${ }^{a}$ The study only included families with one or more children under the age of 6 years. If there was more than one child under the age of 6 , we selected the youngest biological child.

${ }^{b}$ Among families where secondary caregiver lives in the household.

c Excludes cases where the relationship to the secondary caregiver is missing ( $\mathrm{n}=4$ mothers 19-21 years and $\mathrm{n}=16$ mothers $\geq 22$ years).

${ }^{d}$ Only asked in 2008 ( $n=106$ mothers $\leq 18$ years; $n=276$ mothers $19-21$ years; $n=2133$ mothers $\geq 22$ years).

e Based on 7 items (alcohol abuse, drug/solvent abuse, cognitive impairment, mental health issues, few social supports, victim of domestic violence, physical health issues).

* Significantly different from mothers $\geq 22$ years $(p<.05)$.

$x$ Cell count less than 5 .

occur for children in the three groups of families (Table 4).

Among families where the youngest child was substantiated for maltreatment, a child welfare worker was more likely to refer those with a young mother (teen or young adult) than those with a mother aged 22 or older for use of a parent support group and in-home family or parent counselling (Table 5). Referrals for welfare or social assistance were more common for teenmother families, and medical and dental counselling, food bank or shelter services, and psychiatric/psychological services.

Among families with a young mother where alcohol or drug abuse were noted for either the mother or the secondary caregiver, less than one-third were referred for drug or alcohol counselling $(26 \%$ for teen-mother families, $29 \%$ for families with a young adult mother, $31 \%$ for families with mother aged $22+)$. Among families with young mothers where mental health issues were noted for either the mother or the secondary caregiver, less than one-quarter were referred for psychiatric/psychological services (19\% for teen-mother families, $24 \%$ for families with a young adult mother, $23 \%$ for families with mother aged $22+$ ) (data not shown).

As part of the investigation, children in families with a teen mother were more likely to be physically examined by a physician or nurse than children in the comparison group. Out-of-home placement of the child during the investigation was more common among families with a young mother (teen or young adult) than in families with a mother aged 22 or older ( $29 \%$ and $27 \%$ vs. $17 \%)$. Families with a teen mother were less likely to have police involved in an adult domestic violence investigation, and this relationship was maintained when the analysis was restricted to families in which a biological father or mother's intimate partner was living in the home (data not shown). All three groups were equally likely to have police involvement in a child maltreatment investigation.

\section{Discussion}

The members of families investigated by child welfare services are at high risk of experiencing violence, mental health and substance abuse issues, and other difficulties. In this pooled sample of high-risk Canadian families identified in 2003 or 2008, we analyzed, by mother's age, riskrelated variables in the following domains: household, child and family characteristics; mothers' and secondary caregivers' risk factors; services referred and used. Within all domains, an age gradient was evident, with families with the youngest mothers most at risk. However, there was no clear evidence of a mother's age gradient with regard to types of substantiated 
TABLE 4

Type of investigation(s) for youngest child ${ }^{\mathrm{a}}$ among investigated families where the primary caregiver was the biological mother

\begin{tabular}{|c|c|c|c|c|c|c|c|c|c|c|c|c|}
\hline & \multicolumn{6}{|c|}{ Age of biological mother, years, in Investigated cases } & \multicolumn{6}{|c|}{ Age of biological mother, years, in Substantiated cases } \\
\hline & \multicolumn{2}{|c|}{$\leq 18$} & \multicolumn{2}{|c|}{$19-21$} & \multicolumn{2}{|c|}{$\geq 22$} & \multicolumn{2}{|c|}{$\leq 18$} & \multicolumn{2}{|c|}{$19-21$} & \multicolumn{2}{|c|}{$\geq 22$} \\
\hline & $\mathbf{N}$ & $\%$ & $\mathbf{N}$ & $\%$ & $\mathbf{N}$ & $\%$ & $\mathbf{N}$ & $\%^{d}$ & $\mathbf{N}$ & $\%^{\mathbf{d}}$ & $\mathbf{N}$ & $\%^{d}$ \\
\hline Total & 284 & & 800 & & 5752 & & & & & & & \\
\hline Risk investigation ${ }^{b}$ & 89 & $31.3^{*}$ & 146 & 18.3 & 974 & 16.9 & 31 & 34.8 & 46 & 31.5 & 260 & 26.7 \\
\hline Maltreatment investigation & 195 & $68.7^{*}$ & 654 & 81.8 & 4778 & 83.1 & 111 & 56.9 & 360 & 55.0 & 2462 & 51.5 \\
\hline \multicolumn{13}{|l|}{ Type of maltreatment investigation ${ }^{c}$} \\
\hline Neglect & 129 & $45.4^{*}$ & 359 & $44.9^{*}$ & 2075 & 36.1 & 65 & 50.4 & 159 & 44.3 & 968 & 46.7 \\
\hline Exposure to intimate personal violence & 56 & $19.7^{*}$ & 262 & $32.8^{*}$ & 1680 & 29.2 & 36 & 64.3 & 189 & 72.1 & 1192 & 71.0 \\
\hline Emotional maltreatment & 38 & 13.4 & 142 & $17.8^{*}$ & 854 & 14.8 & 20 & 52.6 & 72 & 50.7 & 385 & 45.1 \\
\hline Physical abuse & 25 & $8.8^{*}$ & 67 & $8.4^{*}$ & 1047 & 18.2 & 8 & 32.0 & 12 & 17.9 & 304 & 29.0 \\
\hline Sexual abuse & $\mathrm{x}$ & $x$ & 11 & $1.4^{*}$ & 301 & 5.2 & $\mathrm{x}$ & $x$ & $\mathrm{x}$ & $x$ & 51 & 16.9 \\
\hline
\end{tabular}

Source: Canadian Incidence Study of Reported Child Abuse and Neglect, 2003 and 2008.

a The study only included families with one or more children under the age of 6 years. If there was more than one child under the age of 6 , we selected the youngest biological child.

${ }^{b}$ Risk investigations only collected in 2008.

c Based on primary, secondary and tertiary investigations.

${ }^{\mathrm{d}}$ Number substantiated divided by number investigated.

* Significantly different from mothers aged $\geq 22$ years $(p<.05)$.

$\mathrm{x}$ Cell count less than 5 .

maltreatment, and the relationship between mother's age and intimate partner violence was complex.

Unlike other samples, in which younger couples are more inclined to report violence than are older couples, ${ }^{14,15}$ the youngest mothers in this child welfare sample were not more likely to have been victims of domestic violence. We suggest that this finding was not due to the presence or absence of an intimate partner but rather because another adult was present in the home, the most common situation in the teen-mother families. Although the potential for violence in teen-mother intimate partnerships may be high, the presence of another adult may reduce the expression of violence between intimate partners.

The age gradient for one risk factor for mothers was particularly strong: $10 \%$ of mothers aged 22 years and older had a noted or suspected history of living in foster care or a group home; this was the case for more than $20 \%$ of 19 - to 21-year-old mothers and for more than $30 \%$ of mothers younger than age 18 years. A significant but weaker age gradient was seen for secondary caregivers. Time spent in foster care or a group home suggests a childhood history of maltreatment. The links between a history of maltreatment and early parenthood have been previously explored. ${ }^{16-18}$ Using data from a longitudinal sample of 1000 American adolescents observed since 1988, Thornberry et al. ${ }^{19}$ found that their maltreatment while growing up (including witnessing severe domestic violence) was a risk factor for a substantiated report of their maltreating a child before age 33 years. Precocious transitions to adulthood (i.e. living with a partner before age 19; becoming a parent before age 20) were associated with a fourfold increased risk of committing maltreatment in this mostly male sample. ${ }^{19}$

Thus, for the young mothers and the secondary caregivers described in this sample, personal histories of childhood maltreatment may be associated with both their early parenthood and their involvement with child welfare services. An early intervention program with young mothers like the one in this sample may be more efficient, more cost-effective and less stigmatizing than child welfare interventions that, by definition, can only occur once someone has become concerned and made a report to child welfare services.

A gradient by mothers' age was seen in noted alcohol or drug problems, with the youngest mothers and the secondary caregivers in families with young mothers most likely to have these problems. But referrals to drug/alcohol counselling were equally likely in the groups. It is possible that the mothers and secondary caregivers in young families should be more often referred for such services. However, it is also possible that they are not referred more often because they are already enrolled or because needed services are not available in their communities in ways that are accessible to these young families.

Our study has implications for exploring potentially unmet service needs and how to best address them. In addition, our analysis also has implications for potential diversion of families from initial child welfare involvement. Successful diversion from child welfare involvement would involve prevention of initial child maltreatment, and, ideally, prevention also of risk factors that might lead to referrals to child protection. Given that the youngest mothers may have multiple needs and stresses that would make it difficult for them to reach out to community supports and services, programs intended to prevent maltreatment may need to be proactive in reaching mothers at risk. Mothers who are able to reach out to support services (e.g. to bring their infants to a drop-in centre) may 
TABLE 5

Publicly funded services used/referred among investigated families ${ }^{\mathrm{a}}$ where the primary caregiver was the biological mother and the youngest child was substantiated for maltreatment

\begin{tabular}{|c|c|c|c|c|c|c|}
\hline & \multicolumn{6}{|c|}{ Age of mother, years } \\
\hline & \multicolumn{2}{|c|}{$\leq 18$} & \multicolumn{2}{|c|}{ 19-21 } & \multicolumn{2}{|c|}{$\geq 22$} \\
\hline & $\mathbf{N}$ & $\%$ & $\mathbf{N}$ & $\%$ & $\mathbf{N}$ & $\%$ \\
\hline Total families where youngest child substantiated for maltreatment & 111 & & 360 & & 2462 & \\
\hline \multicolumn{7}{|l|}{ Service referrals for any family member } \\
\hline Parent support group & 29 & $26.1^{*}$ & 62 & $17.2^{*}$ & 298 & 12.1 \\
\hline In-home family or parent counselling & 30 & $27.0^{*}$ & 80 & $22.2^{*}$ & 438 & 17.8 \\
\hline Drug or alcohol counselling & 20 & 18.0 & 78 & 21.7 & 457 & 18.6 \\
\hline Welfare or social assistance & 20 & $18.0^{*}$ & 26 & 7.2 & 124 & 5.0 \\
\hline Food bank & $\mathrm{x}$ & $\mathrm{x}$ & 21 & 5.8 & 129 & 5.2 \\
\hline Shelter services & 10 & 9.0 & 27 & 7.5 & 172 & 7.0 \\
\hline Domestic violence services & 17 & $15.3^{*}$ & 89 & 24.7 & 607 & 24.7 \\
\hline Psychiatric or psychological services & 10 & 9.0 & 42 & 11.7 & 293 & 11.9 \\
\hline Medical or dental services & 5 & 4.5 & 29 & $8.1^{*}$ & 118 & 4.8 \\
\hline Child physically examined by a physician/ nurse & 23 & $20.7^{*}$ & 48 & 13.3 & 276 & 11.2 \\
\hline \multicolumn{7}{|l|}{ Placement during investigation ${ }^{\mathrm{b}}$} \\
\hline Placement made & 31 & $29.0^{*}$ & 93 & $27.3^{*}$ & 369 & 16.5 \\
\hline Placement considered & 7 & $6.5^{*}$ & $\mathrm{x}$ & $\mathrm{x}$ & 44 & 2.0 \\
\hline No placement required/considered & 69 & $64.5^{*}$ & 246 & $72.1^{*}$ & 1820 & 81.5 \\
\hline \multicolumn{7}{|l|}{ Police involvement in adult domestic violence investigation } \\
\hline Investigation only & 13 & 11.7 & 59 & 16.4 & 358 & 14.5 \\
\hline Charges being considered & $\mathrm{x}$ & $\mathrm{x}$ & 5 & 1.4 & 73 & 3.0 \\
\hline Charges laid & 14 & $12.6^{*}$ & 92 & 25.6 & 584 & 23.7 \\
\hline No police involvement & 83 & $74.8^{*}$ & 204 & 56.7 & 1447 & 58.8 \\
\hline \multicolumn{7}{|l|}{ Police involvement in child maltreatment investigation } \\
\hline Investigation only & 16 & 14.4 & 39 & 10.8 & 267 & 10.8 \\
\hline Charges being considered & $\mathrm{x}$ & $\mathrm{x}$ & $\mathrm{x}$ & $\mathrm{x}$ & 46 & 1.9 \\
\hline Charges laid & $\mathrm{x}$ & $\mathrm{x}$ & 9 & 2.5 & 99 & 4.0 \\
\hline No police involvement & 89 & 80.2 & 311 & 86.4 & 2050 & 83.3 \\
\hline
\end{tabular}

Source: Canadian Incidence Study of Reported Child Abuse and Neglect, 2003 and 2008.

a The study only included families with one or more children under the age of 6 years. If there was more than one child under the age of 6 , we selected the youngest biological child.

${ }^{b}$ Excludes cases ( $n=23$ mothers $<22$ years and $n=229$ mothers $\geq 22$ years) from 2008 where limited information on placement was collected in some sites.

* Significantly different from mothers $\geq 22$ years $(p<.05)$.

$x$ Cell count less than 5 .

differ in important ways from mothers who most need support services.

Over two decades of follow-up in the United States has shown that the NurseFamily Partnership (NFP) program reduces a variety of poor outcomes, including maternal and child mortality. ${ }^{20}$ NFP is an intensive program of home visiting in which specially trained public health nurses work with first-time young mothers, beginning prenatally and ending at the child's second birthday. ${ }^{21}$ All NFP mothers consent to enrol and, within this voluntary framework, each is actively engaged by her nurse. Randomized controlled trials in the United States demonstrated that the NFP reduces stateverified reports of child maltreatment ${ }^{22}$ and risk factors for child maltreatment. ${ }^{21,23}$ A randomized controlled trial of NFP is currently underway in British Columbia to determine if NFP is effective within a Canadian context. ${ }^{24}$ As a complement to the randomized controlled trial, the Public
Health Agency of Canada has commissioned a process evaluation to understand how and why the NFP succeeds, or fails, within different contexts within British Columbia.

Compared to other families involved in child welfare, families with young mothers are more likely to demonstrate risk factors that can be modified by an intervention programs. Young mother families have needs that, if an effective intervention had been delivered to them sooner, might never have become so pressing that child welfare services needed to become involved. Fallon et al. ${ }^{10}$ noted that ongoing service provision following a child protection investigation was more likely for young mothers, and provision of such services has costs. Future work may usefully explore the cost benefit ratio (in terms of both financial and human costs) of targeted early provision of prevention services to families most at risk, versus later provision of child welfare intervention services. Early interventions to support young mothers dealing with substance abuse and mental health issues may not only avoid future child welfare investigations but also result in long-term health benefits to the mothers. Such information may prove useful to anyone considering whether or not a program is cost-effective to implement.

\section{Strengths and limitations}

Because women's reproductive history was not assessed in the CIS, a limitation of these analyses is that some of the mothers aged 22 years and older may have been teen mothers at an earlier phase of their lives. We were not able to examine characteristics of families in which the mothers were once teen mothers. As well, the measure of socioeconomic status available in this data set was limited, and our analyses could not consider potential effects of social and cultural support for early childbearing on the risk factors assessed in the CIS. In addition, we assumed that simple random sampling was used to select the sample; this assumption likely means that we have underestimated the variance in our estimates.

A strength of our research is that the comparison group we used for teen and 
young adult mothers involved with child welfare services was other mothers involved with child welfare services. In addition, we made the groups as similar as possible by restricting analyses to families with young children. Young mothers involved with child welfare services may be very different from young mothers described in surveys representative of the general population. In terms of young mothers' use of alcohol, for example, data from 2005-2008 indicate that mothers in the 20- to 24-year age group (the youngest available) are as or less likely than older mothers to report alcohol consumption during pregnancy ( $8 \%$ vs. an average across all available age groups of $11 \%) .^{3}$ In contrast, many of the young mothers in the sample we used were noted for alcohol abuse problems. Understanding the needs of these young families is enhanced by comparing them with a group that is involved with child welfare services, rather than the general population.

\section{References}

1. Koniak-Griffin D, Turner-Pluta C. Health risks and psychosocial outcomes of early childbearing: a review of the literature. J Perinat Neonat Nurs. 2001;15(2):1-17.

2. Jutte DP, Roos NP, Brownell MD, Briggs G, MacWilliam L, Roos LL. The ripples of adolescent motherhood: social, educational, and medical outcomes for children of teen and prior teen mothers. Acad Pediatr. 2010;10(5):293-301.

3. Public Health Agency of Canada. Perinatal health indicators for Canada 2013. Ottawa (ON): Public Health Agency of Canada; 2013.

4. Statistics Canada. Table 2-2: live births, by geography - age of mother [Internet]. Ottawa (ON): Statistics Canada; 2009 [cited 2015 Feb 26]. [Statistics Canada, Catalogue No.: 84F0210X]. Available from: http://www.statcan.gc.ca/pub/84f0210x/ 2009000/t003-eng.htm

5. Sherraden MS, Gonzalez R, Rainford W. Hacia un futuro más seguro: pregnancy and childbearing among Latina adolescents. In: Holgate HS, Evans R, Yuen FKO editors. Teenage pregnancy and parenthood: global perspectives, issues, and interventions. New York (NY): Routledge; 2006. pp. 36-57.
6. MacMillan HL, Tanaka M, Duku E, Vaillancourt T, Boyle MH. Child physical and sexual abuse in a community sample of young adults: results from the Ontario Child Health Study. Child Abuse Negl. 2013; 37(1):14-21.

7. Tonmyr L, Williams G, Jack SM, MacMillan HL. Infant placement in Canadian child maltreatment-related investigations. Int $\mathrm{J}$ Ment Health Addict. 2011;9:441-59.

8. Williams G, Tonmyr L, Jack SM, Fallon B, MacMillan HL. Determinants of maltreatment substantiation in a sample of infants involved with the child welfare system. Child Youth Serv Rev. 2011;33: 1345-53.

9. Superle T. Family violence against children and youth. In: Juristat: Family violence in Canada: A statistical profile, 2013. Ottawa (ON): Canadian Centre for Justice Statistics; 2015. [Statistics Canada, Catalogue No.: 85002-X]p. 39-54.

10. Fallon B, Ma J, Black T, Wekerle C. Characteristics of young parents investigated and opened for ongoing services in child welfare. Int $\mathrm{J}$ Ment Health Addict. 2011; $9(4): 365-81$.

11. Public Health Agency of Canada. Canadian Incidence Study of Reported Child Abuse and Neglect-2008: major findings. 2010. Ottawa (ON): Public Health Agency of Canada; 2010.

12. Trocmé N, Fallon B, MacLaurin B, et al. Canadian Incidence Study of Reported Child Abuse and Neglect - 2003: major findings. Ottawa (ON): Public Health Agency of Canada; 2005.

13. Dumais J. Comparison and assessment of CIS 1998, 2003 and 2008 Designs. 2010. Statistics Canada. Unpublished report.

14. Al-Sahab B, Heifetz M, Tamim H, Bohr Y, Connolly J. Prevalence and characteristics of teen motherhood in Canada. Maternal Child Health. 2012;16(1):228-34.

15. Sinha M. Family violence in Canada: a statistical profile 2011. Juristat. Statistics Canada, Canadian Centre for Justice Statistics; 2013. [Statistics Canada, Catalogue No.: 85-002].
16. Cederbaum JA, Putnam-Hornstein E, King B, Gilbert K, Needell B. Infant birth weight and maltreatment of adolescent mothers. Am J Prev Med. 2013;45(2):197-201.

17. Noll JG, Shenk CE. Teen birth rates in sexually abused and neglected females. Pediatrics. 2013;131(4):e1181-7.

18. Valentino $K$, Nuttall AK, Comas $M$, Borkowski JG, Akai CE. Intergenerational continuity of child abuse among adolescent mothers: authoritarian parenting, community violence, and race. Child Maltreat. 2012;17(2):172-81.

19. Thornberry TP, Matsuda M, Greenman SJ, et al. Adolescent risk factors for child maltreatment. Child Abuse Negl. 2014;38 (4):706-22.

20. Olds DL, Kitzman H, Knudtson MD, Anson E, Smith JA, Cole R. Effect of home visiting by nurses on maternal and child mortality: results of a 2-decade follow-up of a randomized clinical trial. JAMA Pediatr. 2014; 168(9):800-6.

21. Olds DL. The Nurse-Family Partnership: an evidence-based preventive intervention. Infant Ment Health J. 2006;27:5-25.

22. Zielinski DS, Eckenrode J, Olds DL. Nurse home visitation and the prevention of child maltreatment: Impact on the timing of official reports. Dev Psychopathol. 2009;21: 441-53.

23. Olds DL, Sadler S, Kitzman H. Programs for parents of infants and toddlers: recent evidence from randomized trials. J Child Psychol Psychiatry. 2007;48:355-91.

24. Jack SM, Catherine N, Gonzalez A, et al. Adapting, piloting and evaluating complex public health interventions: lessons learned from Nurse-Family Partnership in Canadian public health settings. Health Promot Chronic Dis Prev Can. 2015;35(8/9):151-9. 